\title{
Angiographically borderline left main coronary artery lesions: correlation of transthoracic doppler echocardiography and intravascular ultrasound: a pilot study
}

\author{
Zoltán Ruzsa ${ }^{1}$, Attila Pálinkás ${ }^{2}$, Tamás Forster ${ }^{1}$, Imre Ungi ${ }^{1}$ and Albert Varga ${ }^{1 *}$
}

\begin{abstract}
Background: the clinical decision making could be difficult in patients with borderline lesions (visually assessed stenosis severity of 30 to 50\%) of the left main coronary artery (LM). The aim of the study was to evaluate the relationship between transthoracic Doppler (TTDE) peak diastolic flow velocity (PDV) and intravascular ultrasound (IVUS) measurements in the assessment of angiographically borderline LM lesions.
\end{abstract}

Methods: 27 patients (mean age $64 \pm 8$ years, 21 males) with borderline LM stenosis referred for IVUS examination were included in the study. We performed standard IVUS with minimal lumen area (MLA) and plaque burden (PB) measurement and routine quantitative coronary angiography (QCA) with diameter stenosis (\%DS) and area stenosis (\%AS) assessment in all. During TTDE, resting PDV was measured in the LM.

Results: interpretable Doppler signal could be obtained in 24 patients (88\% feasibility); therefore these patients entered the final analysis. MLA was $7.1 \pm 2.7 \mathrm{~mm}^{2}$. TTDE measured PDV correlated significantly with IVUS-derived MLA ( $r=-0.46, p<0.05)$ and plaque burden $(r=0.51, p<0.05)$. Using a velocity cut-off of $112 \mathrm{~cm} / \mathrm{sec}$ TTDE showed a $92 \%$ sensitivity and $62 \%$ specificity to identify IVUS-significant (MLA $<6 \mathrm{~mm}^{2}$ ) LM stenosis.

Conclusion: In angiographically borderline LM disease, resting PDV from transthoracic echocardiography is increased in presence of increased plaque burden by IVUS. TTDE evaluation might be a useful adjunct to other invasive and non-invasive methods in the assessment of borderline LM lesions. Further, large scale studies are needed to establish the exact cut-off value of PDV for routine clinical application.

\section{Introduction}

Coronary angiography is the gold standard procedure to assess the severity of coronary artery disease, despite of its well-known limitations [1]. Significant left main coronary artery (LM) disease, (defined angiographically as stenosis severity $>50 \%$ ) of luminal diameter, is associated with poor prognosis when medically treated and usually requires coronary bypass surgery $[2,3]$. However, the clinical decision making could be difficult in patients with borderline lesions (visually assessed stenosis severity of 30 to $50 \%$ ) of the LM. Intravascular ultrasound

\footnotetext{
* Correspondence: vargaa@in2nd.szote.u-szeged.hu

'Department of Medicine and Cardiology Center, Faculty of Medicine, Albert Szent-Györgyi Clinical Center, University of Szeged, Szeged, H-6724, Szeged, Pécsi str. 4, Hungary

Full list of author information is available at the end of the article
}

(IVUS) confers the ability to examine accurately the coronary artery architecture, atherosclerotic plaque composition and changes in vessel dimensions as a result of the atherosclerotic process [4-8]. Hence, IVUS is the preferred method to assess the severity of angiographically borderline LM lesions [9-13]. Although it provides detailed anatomical information on the vessel lumen, it is an expensive and invasive procedure. Several other diagnostic tools, such as myocardial perfusion scintigraphy $[14,15]$, stress echocardiography [16], multidetector computed tomography [17] and coronary flow reserve measurement $[18,19]$ have been proposed as valuable adjunct to coronary angiography in the difficult clinical decision making process of patients with borderline LM lesions. It has also been demonstrated, that simple

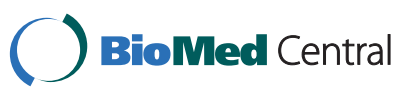

(c) 2011 Ruzsa et al; licensee BioMed Central Ltd. This is an Open Access article distributed under the terms of the Creative Commons Attribution License (http://creativecommons.org/licenses/by/2.0), which permits unrestricted use, distribution, and reproduction in any medium, provided the original work is properly cited. 
resting Doppler transthoracic echocardiography (TTDE) is an effective method in assessing hemodynamically significant LM lesions [20-22]. Its diagnostic and prognostic effectiveness, however, is unknown in case of borderline LM stenosis. The present study was designed to evaluate the potential correlations between IVUS, quantitative coronary angiography (QCA) and TTDE in angiographically borderline LM lesions, and to determine, whether TTDE could have play a role in the decision making process.

\section{Patients and Methods}

\section{Patient population}

Consecutive patients with angiographically documented borderline LM stenosis (30 to 50\%) ( $\mathrm{n}=27$, mean age: $64 \pm 8$ years, 19 males) were enrolled in the present study. Following coronary angiography, LM has been evaluated by IVUS and TTDE in all patients. All patients with positive treadmill stress test and angiographically documented borderline LM stenosis entered this pilot study. Indications and contraindications of the angiography followed the coronary revascularization guideline of the European Society of cardiology [23]. Exclusion criteria were: hemodynamic instability, acute myocardial infarction, hypertrophic cardiomyopathy, severe obesity $\left(\mathrm{BMI}>35 \mathrm{~kg} / \mathrm{m}^{2}\right)$, or known congenital heart disease. Patients were informed about the study itself, its proceedings, and possible adverse events. The study satisfied with Declaration of Helsinki and was approved by ethical committee of the University of Szeged.

\section{Transthoracic Doppler echocardiography}

TTDE studies were performed with a Vivid 8 ultrasound equipment (General Electric, New York, USA) using a 3.5 $\mathrm{MHz}$ transducer with harmonic imaging. All TTDE studies were carried out by a single investigator experienced in LM TTDE assessment, blinded to the angiographic and IVUS results. B-mode image was used to identify the LM and pulsatile Doppler to measure the flow velocity in diastole. Imaging plane was oriented in parallel with short-axis view of the aortic root slightly above the aortic valve. Sample images were stored digitally for subsequent analysis.

\section{Quantitative coronary angiography}

Hemodynamic procedures have been performed with an angiographic system equipped with a digital flat panel imaging detector (Innova 2000; General Electric). All patients underwent standard coronary angiography, at the beginning of which intracoronary nitroglycerine $(0.2$ $\mathrm{mg}$ ) was administered to achieve maximum vasodilatation. Measurements were then taken from two orthogonal views. Data were recorded on CD-ROM to allow off-line assessment. An experienced invasive cardiologist blinded to IVUS and TTDE findings performed off-line the QCA analysis. The edge-detection technique developed by Reiber (CMS-GFT, Medis (Leiden, The Netherlands)) was used for QCA assessment [24-26]. An empty guiding catheter was used for calibration, and diameter stenosis was determined using a quantitative analysis program (Centricity Cardiology, CA1000, General Electrics, USA). Stenosis was considered significant if QCA showed diameter stenosis greater than 50\%.

\section{Intravascular ultrasound}

IVUS was performed together with coronary angiography at one sitting using an Atlantis Plus $40 \mathrm{MHz}$ catheter (Boston Scientific Inc., Natick-MA, USA). After cannulation of LM, a 0.014" guide wire was introduced into the distal LAD and an IVUS catheter was placed into the distal position. The IVUS catheter was withdrawn at 0.25 $\mathrm{mm} / \mathrm{s}$ by automated pullback, while IVUS measurements were recorded on super VHS. Quantitative measurements were taken off-line according to the IVUS standards of the American Society of Cardiology [27]. In each case minimum lumen diameter (MLD in $\mathrm{mm}$ ), minimum lumen area (MLA in $\mathrm{mm}^{2}$ ), external elastic membrane cross-sectional area (EEM-CSA in $\mathrm{mm}^{2}$ ), plaque burden (\%) and area stenosis (\%) were measured. A physician, who was experienced in IVUS, but independent of the study, measured vessel diameter at its narrowest region. LAD stenosis was considered significant if LCSA was smaller than $4 \mathrm{~mm}^{2}$ [28], while stenosis less than $6 \mathrm{~mm}^{2}$ indicated significant LM stenosis [11].

\section{Statistical analysis}

Categorical data are presented with absolute frequencies and percentages, continuous variables as medians with interquartile ranges or as means \pm standard deviation. Differences between continuous variables were analyzed by Student's t test. The relationship between the results obtained by QCA, TTDE and IVUS and was evaluated using Pearson's correlation rank test. Bland-Altman analysis was performed to test agreement between modalities. $\mathrm{P}<0.05$ was considered to reveal significant statistical difference. Statistical analyses were performed using the Sigma-Stat software package (San Jose, California, USA, Systat Software In.).

\section{Results}

Clinical and demographic patient data are demonstrated in Table 1. All study patients had a positive treadmill test or had ST segment depression under chest pain.

\section{Transthoracic echocardiography}

Interpretable Doppler signal could be obtained in 24 patients (88\% feasibility). 
Table 1 Clinical characteristics of study population

\begin{tabular}{ll}
\hline Parameters & $\mathbf{n}(\%)$ \\
\hline Age (year) & $64 \pm 8$ \\
\hline Male gender (\%) & $18(75)$ \\
\hline Systemic hypertension (\%) & $16(67)$ \\
\hline Hypercholesterolemia (\%) & $14(58)$ \\
\hline Current smoker (\%) & $8(33)$ \\
\hline Diabetes mellitus (\%) & $7(29)$ \\
\hline Canadian angina classification: & $0(0)$ \\
- I. & $5(21)$ \\
- II. & $11(46)$ \\
- III. & $8(33)$ \\
- IV. & $9(37.5)$ \\
\hline Previous myocardial infarction (\%) & $0(0)$ \\
\hline Previous coronary bypass surgery (\%)
\end{tabular}

\section{Coronary angiography}

All patients had visually assessed borderline LM stenosis. Isolated left main disease was present in 14 patients, but coronary angiography revealed additional atherosclerotic lesions in the remaining 13 patients: 3 vessel disease in 2 patients, 2 vessel disease in 3 patients and one vessel disease in 5 patients. The summary of LM TTDE, QCA and IVUS measurements are demonstrated in Table 2.

\section{Intravascular ultrasound}

Clear IVUS images were obtained in all cases and no complications occurred during the recordings. IVUS revealed significant LM stenosis in 17 patients $(71 \%)$ Fourteen patients with significant LM stenosis underwent percutaneous coronary intervention (PCI), 3 patients were referred for bypass surgery, while 7 patients were considered having hemodynamically insignificant lesions, and therefore were recommended for further medical treatment and follow up $(29 \%)$.

Table 2 Quantitative coronary angiography, IVUS and TTDE findings

\begin{tabular}{ll}
\hline QCA & \\
\hline - MLD (mm) & $2.6 \pm 0.7$ \\
- Diameter stenosis (\%) & $36.5 \pm 9.6$ \\
- Area stenosis (\%) & $58.15 \pm 12.25$ \\
- Reference diameter (mm) & $4.10 \pm 1.10$ \\
- Lesion length (mm) & $7.2 \pm 3.2$ \\
\hline IVUS (quantitative analysis) & \\
\hline LM MLA site & \\
- MLA (mm ${ }^{2}$ ) & $7.1 \pm 2.7$ \\
MLD (mm) & $2.75 \pm 0.7$ \\
\hline
\end{tabular}

Correlations between angiographic, IVUS and echocardiographic parameters

There was no significant correlation between TTDE and QCA $(r=0.19, p=n s$, Figure 1). TTDE measured PDV correlated significantly with IVUS-derived MLA $(\mathrm{r}=$ $-0.46, \mathrm{p}<0.05$, Figure 2$)$ and plaque burden $(\mathrm{r}=0.51, \mathrm{p}$ $<0.05$, Figure 3). According to the ROC analysis the best cut off for PDV was $112 \mathrm{~cm} / \mathrm{s}$ (sensitivity, 92\%; specificity, 62\%) (Figure 4). Correlation data are summarized in Table 3 and 4.

\section{Discussion}

In our present study we demonstrated, that the measurement of simple resting TTDE might be of additional value in patients with borderline LM lesions.

\section{Limitations of coronary angiography in LM disease}

In many cases, the planar 2D silhouette of the arterial lumen may be unable to accurately define the severity of coronary stenosis, regardless of whether visual or quantitative methods are used. LM has unique anatomical features, which influences the visual and angiographic assessment of lesion severity [29]. LM is a relatively short vessel, and diffuse disease (tubular lesions) often precludes identification of a normal reference segment, leading to underestimation of lesion severity by angiography. Furthermore, the LM is relatively large vessel, therefore non-parallel catheter alignment may lead to an apparent ostial lesion due to contrast streaming, while the overlap of the left anterior descending and left circumflex ostia may obscure the LM bifurcation. Additionally, haziness is often the result of an eccentric plaque seen en face rather than in profile, leading to a reduced volume of contrast dye at the lesion site without producing a stenosis that is quantifiable angiographically. Several studies have shown a poor correlation between IVUS and QCA-derived lumen dimensions in patients with angiographically detected LM stenosis, demonstrating significant intraobserver as well as interobserver variability in the angiographic assessment of the LM [30,31].

\section{Other invasive methods for the assessment of borderline LM lesions}

There is body of evidences regarding the usefulness of both IVUS and fractional flow reserve measurement (FFR) in the evaluation of borderline lesions [11,25,29]. FFR measured by coronary pressure wire provides information regarding functional significance of LM stenosis and is often complimentary to the information provided by IVUS [11]. However, there are still some debates about the determination of criteria for significance. For instance, Jasti et al found that IVUS MLA smaller than $6 \mathrm{~mm}^{2}$ correlated well with FFR $<0.75$ [11]. However, 


\section{TTE PDV vs. QCA DS}

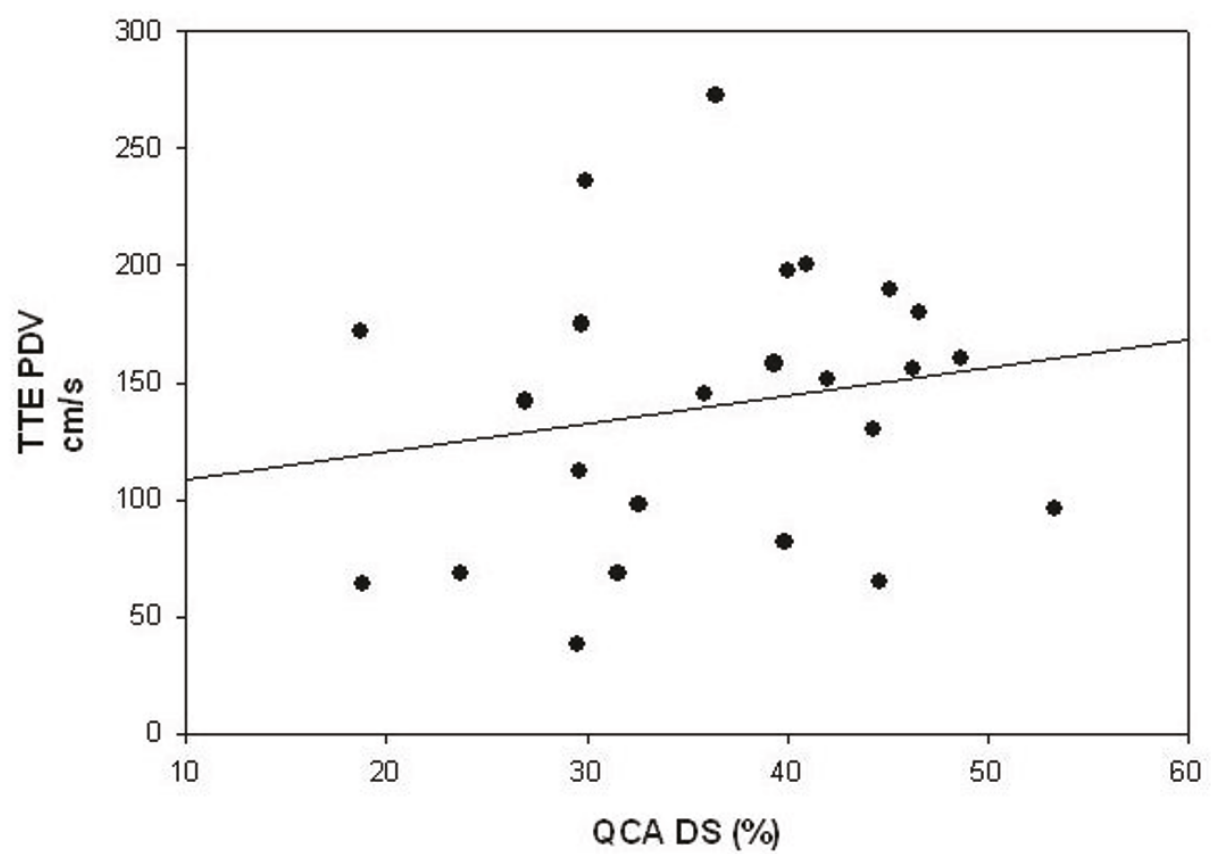

$\mathrm{R}=0.19$

$\mathrm{p}=\mathrm{ns}$

Figure 1 Comparison of peak diastolic velocity (TTDE) and diameter stenosis (QCA) show no significant correlation

TTE PDV vs. IVUS MLA

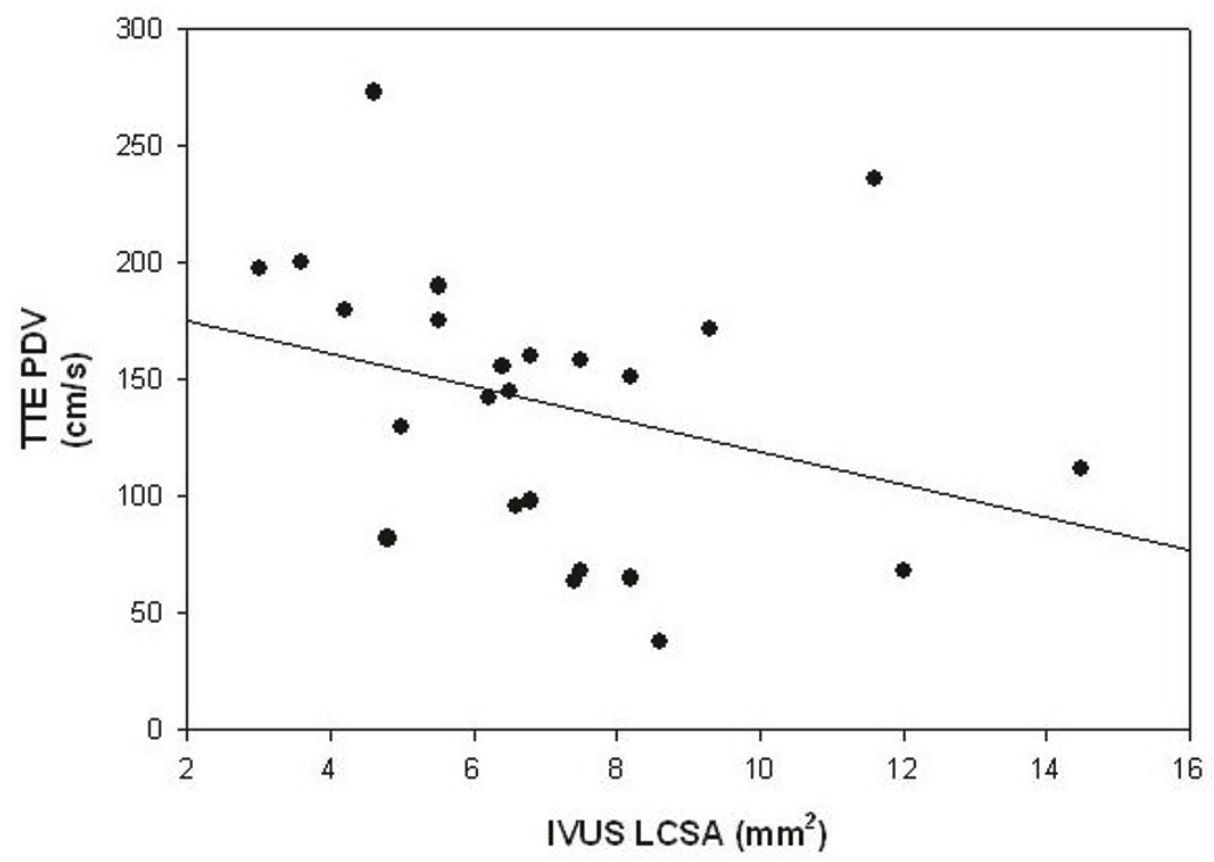

$R=-0,46$

$p=<0.05$

Figure 2 Comparison of peak diastolic velocity (TTDE) and minimum lumen area (IVUS) show significant correlation. 


\section{TTE PDV vs. IVUS Plaque burden}

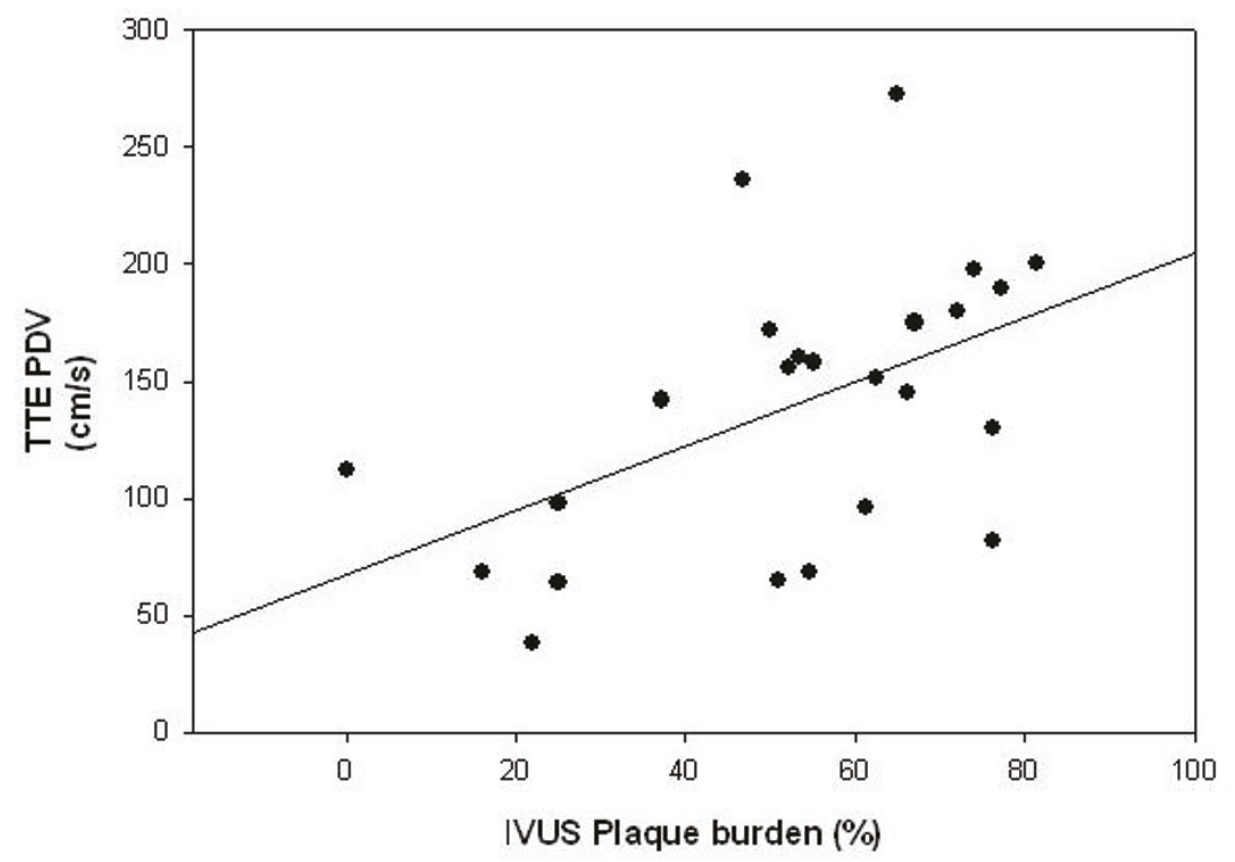

$\mathrm{R}=0.51$

$P<0.05$

Figure 3 Comparison of peak diastolic velocity (TTDE) and plaque burden (IVUS) show significant correlation.

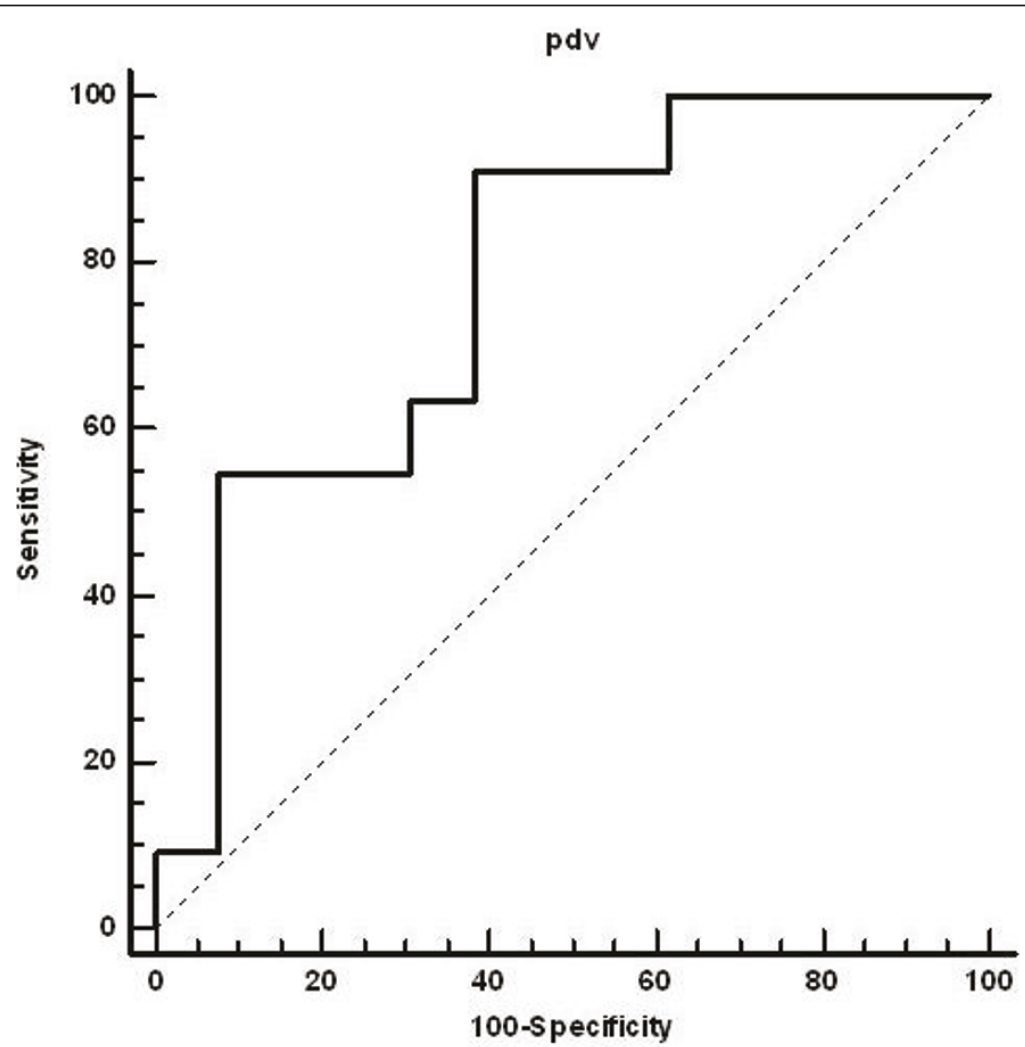

Figure 4 ROC analysis of peak diastolic velocity (TTDE) and minimum lumen area (IVUS) 
Table 3 Correlations of TTDE PDV with QCA and IVUS parameters

\begin{tabular}{llll}
\hline Angiography (QCA) & \multicolumn{2}{l}{ IVUS } & \\
\hline Diameter stenosis & $\mathrm{R}=$ & Plaque burden & $\mathrm{R}=$ \\
& 0.19 & & 0.507 \\
& $\mathrm{p}=$ n.s. & $\mathrm{p}<0.05$ \\
\hline Area stenosis & $\mathrm{R}=$ & Minimum lumen area & $\mathrm{R}=-0.46$ \\
& 0.16 & & \\
& $\mathrm{p}=$ n.s. & $\mathrm{p}<0.05$ \\
\hline Minimum lumen & $\mathrm{R}=$ & Minimum lumen & $\mathrm{R}=-0.18$ \\
diameter & 0.01 & diameter & \\
& $\mathrm{p}=$ n.s. & & $\mathrm{p}=\mathrm{n} . \mathrm{s.}$ \\
\hline
\end{tabular}

Fassa et al. reported a different criterion (MLA by IVUS $<7.5 \mathrm{~mm}^{2}$ ) for a significant LM [10]. In any case, analyses by Sano et al. showed that approximately half of the ambiguous LM narrowing's observed by QCA were hemodynamically significant by IVUS assessment [13]. Our data are in keeping with this observation, since 71\% of our patients had significant LM stenosis by IVUS.

\section{Assessment of the LM with non-invasive methods}

There are several non-invasive diagnostic modalities, which can be helpful in assessing LM lesion severity and all these methods can provide important prognostic information, as well. For instance, Dragu et al. found that multidetector computed tomography assessment of LM correlated well with LM IVUS assessed plaque burden [17]. Jasti et. al. found significant correlation between IVUS assessed plaque burden and FFR in cases of ambiguous left main stenosis [11]. Inducible ischemia, detected either during stress perfusion scintigraphy $[14,15]$ or stress echocardiography [16] is also an important factor in the determination of the physiologic severity of LM disease. Coronary flow reserve, assessed by transthoracic Doppler echocardiography has been also extensively studied and proposed as a valuable adjunct in ambiguous cases following coronary angiography [18]. Recently, Anjaneyulu et al. reported that LM stenosis could be assessed by transthoracic echocardiography with an acceptable degree of sensitivity and specificity [21]. Furthermore, Caiati et al [22] have found that the entire LAD can be visualized by the use of contrast- enhanced TTDE and taking a flow acceleration of $0.82 \%$ as reference value, for Doppler criterion of significant stenosis, the sensitivity and specificity of the method in identifying all diseased segments was 86 and 95\%. However, left main stenosis was not analyzed in their population separately. Therefore, our study expands these findings demonstrating that even in cases with ambiguous coronary angiographic results, a simple measurement of the diastolic flow in the LM by pulsatile Doppler echocardiography can provide additional valuable information and can facilitate the decision making process regarding further treatment.

\section{Clinical implications}

Assessing borderline coronary stenosis is an ongoing challenge in invasive cardiology. The optimal techniques are IVUS and FFR measurements, however these techniques are extremely expensive, not widely available, and require special training. Non-invasive techniques like TEE or TTDE using a high frequency transducer are useful for noninvasive evaluation of flow velocity dynamics in the LM [12,20-22,32]. Doppler-TTE is a simple, widely-used, and noninvasive procedure that does not require lengthy preparation and post-examination observation, therefore can be used for routine screening of patients with known ambiguous LM as adjunct to other invasive or non-invasive diagnostic modalities. The cutoff value of $112 \mathrm{~cm} / \mathrm{sec}$ determined by the ROC analysis demonstrated a good sensitivity of PDV in recognizing hemodynamically significant (determined by IVUS) LM disease, however the specificity of the method was rather low. This can still generate further unnecessary invasive testing's, therefore at this point the PDV cannot considered a standalone method in the evaluation process of the borderline LM narrowing's. A typical borderline LM case is presented in Figure 5 and a possible clinical algorithm is given in Figure 6. Further, large scale studies are needed to establish the exact cut-off value of PDV for routine clinical application.

\section{Study limitations}

The severity of the LM lesion was determined by measuring the flow velocity by Doppler echocardiography,

Table 4 Correlations between IVUS and QCA parameters

\begin{tabular}{llll}
\hline & $\begin{array}{l}\text { IVUS } \\
\text { Plaque burden }\end{array}$ & $\begin{array}{l}\text { IVUS } \\
\text { Minimum lumen area }\end{array}$ & $\begin{array}{l}\text { IVUS } \\
\text { Minimum lumen diameter }\end{array}$ \\
\hline Angiography & $\mathrm{R}=0.61$ & $\mathrm{R}=-0.48$ & $\mathrm{R}=-0.51$ \\
\hline Diameter stenosis & $\mathrm{p}<0.05$ & $\mathrm{p}<0.05$ & $\mathrm{p}<0.05$ \\
\hline Angiography & $\mathrm{R}=0.57$ & $\mathrm{R}=-0.41$ & $\mathrm{R}=-0.45$ \\
\hline Area stenosis & $\mathrm{p}<0.05$ & $\mathrm{p}<0.05$ & $\mathrm{p}<0.05$ \\
\hline Angiography & $\mathrm{R}=-0.35$ & $\mathrm{R}=0.64$ & $\mathrm{R}=0.40$ \\
\hline Minimum lumen diameter & $\mathrm{p}=$ n.s. & $\mathrm{p}<0.001$ & $\mathrm{p}<0.05$ \\
\hline
\end{tabular}




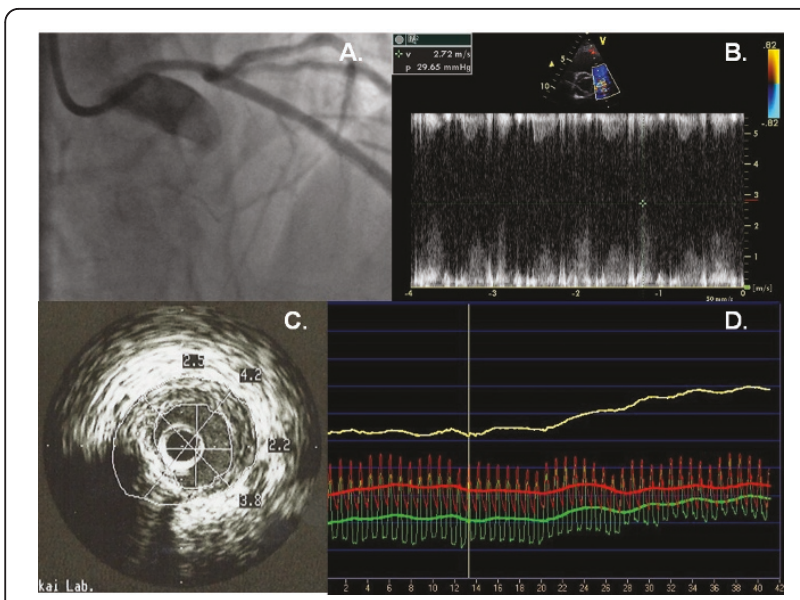

Figure 5 The imaging sequel of a 64-year old male patient with ambiguous angiography result. Coronary angiography revealed a tubular 30\% stenosis of the LM, and non significant stenosis of the left and right coronary artery (panel A). However, the clinical presentation (severe angina, Canadian classification III-IV) did not corroborate with the angiographical findings, therefore the patient was sent to TTDE, which confirmed very high $(272 \mathrm{~cm} / \mathrm{s}) \mathrm{LM}$ resting PDV (panel B). IVUS and FFR were performed, which both confirmed the severity of the LM stenosis (FFR $=0.72$; IVUS plaque burden: 65\% and LCSA: $4.6 \mathrm{~mm} 2$ ) (panel C and D). but we don't have evidences how microvascular resistance or other hemodynamic conditions changes the level of PDV. The value of resting Doppler velocity is determined by the severity of the coronary stenosis and other rheological and haemodynamic factors, of which abnormality of the microcirculation may falsely increase the value of PDV, potentially disturbing its assessment. The value of resting PDV can be influenced by haemodynamic variables, as well, such as changes in heart rate, blood pressure and increased contractility. Geometry of the vessel (tortuousity, kinking) and the plaque incidence of the ultrasound beam (eccentric plaque) are also important factors that may influence PDV. The most important limitation of PDV measurement is technical. Very accurate adjustment of the Doppler beam is needed during the measurement, what is in some cases can cause difficulties. For instance, when the orientation of LM is orthogonal in the short-axis view where angle correction exceeded 60 degrees, diastolic flow velocity could be underestimated [21]. Not all echocardiography systems are equipped with the appropriate software and experienced personnel to perform this technique. Today, however, TTE assessment of the LM is a common and accepted and spreading method.

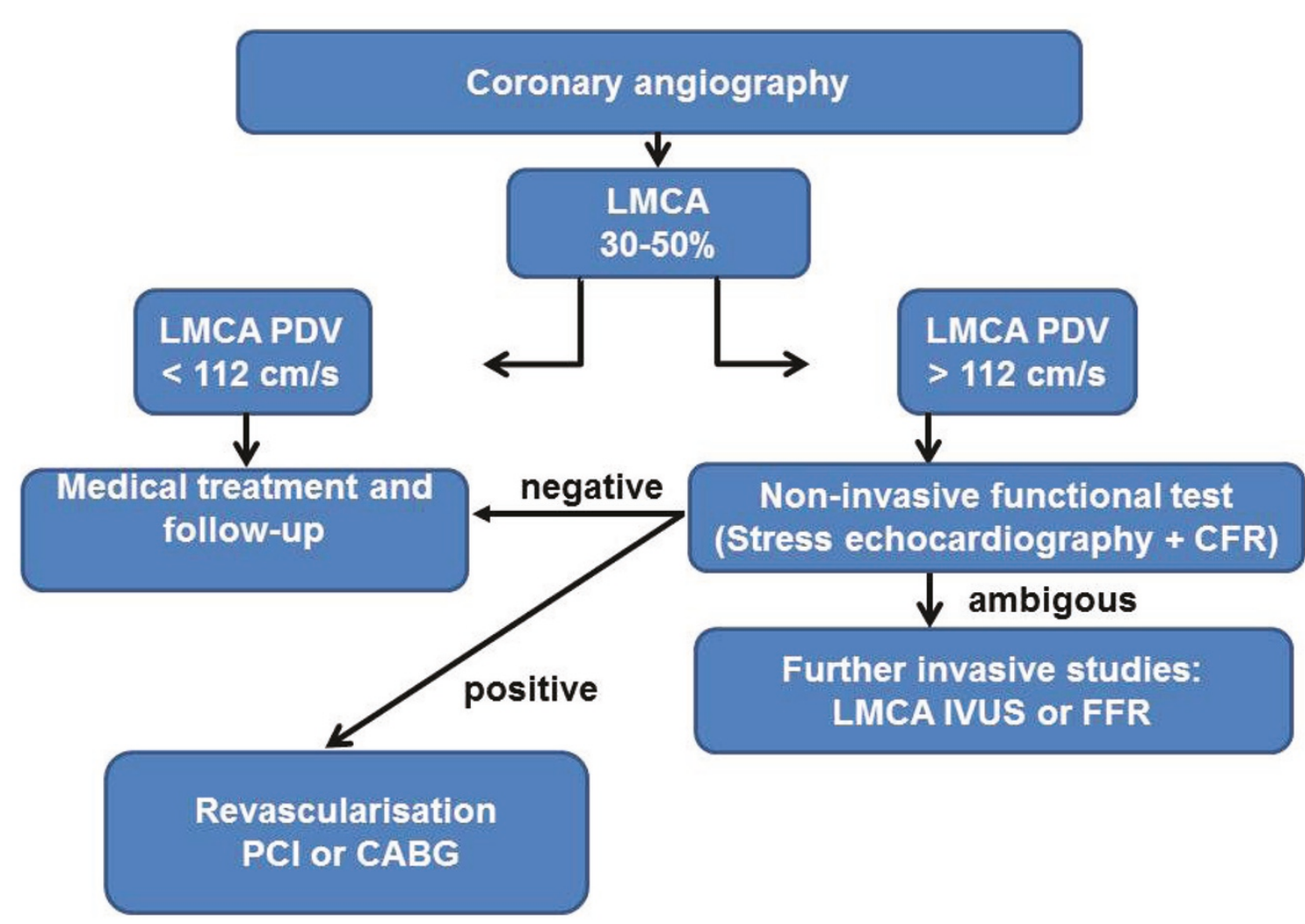

Figure 6 Left main coronary disease: diagnostic flow chart which incorporates the Doppler echocardiographic parameters. 
Additional limitation is that our patient group was selected and relatively small, but we focused on the reliability of TTE assessment and not on determining the PDV characteristics of different pathologies. Furthermore, neither functional studies nor coronary flow reserve evaluation were performed in our study population, therefore we don't have data regarding the comparison of the physiologic severity of the lesions and the PDV.

\section{Conclusion}

TTDE evaluation might be a useful adjunct to other invasive and non-invasive methods in the assessment of borderline LM lesions. Further, large scale studies are needed to establish the exact cut-off value of PDV for routine clinical application.

\section{List of abbreviations}

CFR: coronary flow reserve; DS; diameter stenosis; FFR: fractional flow reserve: IVUS: intravascular ultrasound; LM: Left main coronary artery; LAD: left anterior descending artery; MLA: minimum lumen area; PDV: peak diastolic velocity; QCA: quantitative coronary angiography; TTE: transthoracic echocardiography; TEE: transoesophageal echocardiography; TTDE: transthoracic Doppler echocardiography.

\section{Author details}

'Department of Medicine and Cardiology Center, Faculty of Medicine, Albert Szent-Györgyi Clinical Center, University of Szeged, Szeged, H-6724, Szeged, Pécsi str. 4, Hungary. ${ }^{2}$ Department of Internal Medicine, Erzsébet Hospital, Hódmezővásárhely, Hungary.

\section{Authors' contributions}

$\mathrm{ZR}, \mathrm{AP}$ and $\mathrm{AV}$ introduced the study idea. AP acquired the ultrasound images. IU and AP performed the off-line analysis. AP helped in the interpretation of the results and statistical analysis. ZR wrote the manuscript, AV added clinical discussion to the manuscript. IU and TF reviewed the manuscript. Finally, all authors read and approved the manuscript.

\section{Competing interests}

The authors declare that they have no competing interests.

Received: 31 January 2011 Accepted: 14 June 2011 Published: 14 June 2011

\section{References}

1. Topol EJ, Nissen SE: Our preoccupation with coronary luminology. The dissociation between clinical and angiographic findings in ischemic heart disease. Circulation 1995, 92:2333-42.

2. Yusuf S, Zucker D, Peduzzi P, Fisher LD, Takaro T, Kennedy JW, Davis K, Killip T, Passamani E, Norris R, et al: Effect of coronary artery bypass graft surgery on survival: overview of 10-year results from randomized trials by the Coronary Artery Bypass Graft Surgery Trialists Collaboration. Lancet 1994, 344:563-70.

3. Caracciolo EA, Davis KB, Sopko G, et al: Comparison of surgical and medical group survival in patients with left main coronary artery disease. Long-term CASS experience. Circulation 1995, 91:2325-34.

4. Arnett EN, Isner JM, Redwood DR, Kent KM, Baker WP, Ackerstein H, Roberts WC: Coronary artery narrowing in coronary heart disease: Comparison of cineangiographic and necropsy findings. Ann Intern Med 1979, 91:350-356.

5. Fisher LD, Judkins MP, Lesperance J, Cameron A, Swaye P, Ryan T, Maynard C, Bourassa M, Kennedy JW, Gosselin A, Kemp H, Faxon D, Wexler L, Davis KB: Reproducibility of coronary arteriographic reading in the coronary artery surgery study (CASS). Cathet Cardiovasc Diagn 1982, 8:565-75.
6. Nissen SE, Gurley JC, Grines CL, Grines CL, Booth DC, McClure R, Berk M, Fischer C, DiMaria AN: Intravascular ultrasound assessment of lumen size and wall morphology in normal subjects and patients with coronary artery disease. Circulation 1991, 84:1087-1099.

7. Mintz GS, Painter JA, Pichard AD, Kent KM, Satler LF, Popma JJ, Chuang YC, Bucher TA, Sokolowicz LE, Leon MB: Atherosclerosis in angiographically "normal" coronary artery reference segments: an intravascular ultrasound study with clinical correlations. J Am Coll Cardiol 1995, 25:1479-85.

8. Alfonso F, Macaya C, Goicolea J, Iñiguez A, Hernandez R, Zamorano J, Perez-Vizcayne MJ, Zarco P: Intravascular ultrasound imaging of angiographically normal coronary segments in patients with coronary artery disease. Am Heart J 1994, 127:536-544.

9. Leesar MA: Intravascular Ultrasound for the Assessment of an Ambiguous Left Main Coronary Stenosis. J Am Coll Cardiol 2005, 46:2145-2145.

10. Fassa AA, Wagatsuma K, Higano ST, et al: Intravascular ultrasound-guided treatment for angiographically indeterminate left main coronary artery disease. J Am Coll Cardiol 2005, 45:204-211.

11. Jasti V, Ivan E, Yalamanchili V, Wongpraparut N, Leesar MA: Correlations between fractional flow reserve and intravascular ultrasound in patients with an ambiguous left main coronary artery stenosis. Circulation 2004, 110:2831-2836.

12. Weyman AE, Feigenbaum H, Dillon JC, Johnston KW, Eggleton RC: Noninvasive visualization of the left main coronary artery by crossSectional echocardiography. Circulation 1976, 54:169-174.

13. Sano K, Mintz GS, Carlier SG, de Ribamar Costa J Jr, Qian J, Missel E, Shan S, Franklin-Bond T, Boland P, Weisz G, Moussa I, Dangas GD, Mehran R, Lansky AJ, Kreps EM, Collins MB, Stone GW, Leon MB, Moses JW: Assessing intermediate left main coronary lesions using intravascular ultrasound. Am Heart J 2007, 154:983-8.

14. Shiba C, Chikamori T, Hida S, Igarashi Y, Tanaka H, Hirose K, Ohtaki Y, Usui Y, Miyagi M, Hatano T, Yamashina A: Important parameters in the detection of left main trunk disease using stress myocardial perfusion imaging. J Cardiol 2009, 53:43-52.

15. Berman DS, Kang X, Slomka PJ, Gerlach J, de Yang L, Hayes SW, Friedman JD, Thomson LE, Germano G: Underestimation of extent of ischemia by gated SPECT myocardial perfusion imaging in patients with left main coronary artery disease. J NuCl Cardiol 2007, 14:521-8.

16. Andrade MJ, Picano E, Pingitore A, Petix N, Mazzoni V, Landi P, Raciti M: Dipyridamole stress echocardiography in patients with severe left main coronary artery narrowing. Echo Persantine International Cooperative (EPIC) Study Group-Subproject "Left Main Detection". Am J Cardiol 1994, 73:450-5.

17. Dragu R, Kerner A, Gruberg L, Rispler S, Lessick J, Ghersin E, Litmanovich D, Engel A, Beyar R, Roguin A: Angiographically uncertain left main coronary artery narrowings: correlation with multidetector computed tomography and intravascular ultrasound. Int J Cardiovasc Imaging 2008, 24:557-63.

18. Rigo F: Coronary flow reserve in stress-echo lab. From pathophysiologic toy to diagnostic tool. Cardiovasc Ultrasound 2005, 3:8.

19. Nakatani S, Yamagishi M, Tamai J, Takaki H, Haze K, Miytatake K: Quantitative assessment of coronary artery stenosis by intravascular Doppler catheter technique: application of the continuity equation. Circulation 1992, 85:1786-1791.

20. Saraste M, Vesalainen RK, Ylitalo A, Saraste A, Koskenvuo JW, Toikka JO, Vaittinen MA, Hartiala JJ, Airaksinen KE: Transthoracic Doppler echocardiography as a noninvasive tool to assess coronary artery stenoses-a comparison with quantitative coronary angiography. J Am Soc Echocardiogr 2005, 18:679-85.

21. Anjaneyulu A, Raghu K, Chandramukhi S, Satyajit GM, Arramraja S, Raghavaraju P, Krishnamraju P, Somaraju B: Evaluation of left main coronary artery stenosis by transthoracic echocardiography. J Am Soc Echocardiogr 2008, 21:855-60.

22. Caiati C, Zedda N, Cadeddu M, Chen L, Montaldo C, lliceto S, Lepera ME, Favale S: Detection, location, and severity assessment of left anterior descending coronary artery stenoses by means of contrast-enhanced transthoracic harmonic echo Doppler. Eur Heart J 2009, 30:1797-1806.

23. Kolh P, Wijns W, Danchin N, Di Mario C, Falk V, Folliguet T, Garg S, Huber K, James S, Knuuti J, Lopez-Sendon J, Marco J, Menicanti L, Ostojic M, Piepoli MF, Pirlet C, Pomar JL, Reifart N, Ribichini FL, Schalij MJ, Sergeant P, Serruys PW, Silber S, Sousa Uva M, Taggart D: Guidelines on myocardial 
revascularization. Task Force on Myocardial Revascularization of the European Society of Cardiology (ESC) and the European Association for Cardio-Thoracic Surgery (EACTS); European Association for Percutaneous Cardiovascular Interventions (EAPCI). Eur I Cardiothorac Surg 2010, 38(Suppl):S1-S52.

24. Hasse J, van der Linden MM, Di Mario C, van der Giessen WJ, Foley DP, Serruys PW: Can the same edge-detection algorithm be applied to online analysis systems? Am Heart J 1993, 126:312-21.

25. Lesperance J, Waters D: Measuring progression and regression of coronary atherosclerosis in clinical trials: problems and progress. Int $J$ Card Imaging 1992, 8:165-73.

26. Koning G, van der Zwet PM, von Land CD, Reiber JH: Angiographic assessment of dimensions of $6 \mathrm{~F}$ and $7 \mathrm{~F}$ Mallinckrodt Softouch coronary contrast catheters from digital and cine arteriograms. Int I Card Imaging 1992, 8:153-61.

27. Mintz GS, Nissen SE, Anderson WD, et al: American College of Cardiology clinical expert consensus document on standards for acquisition, measurement and reporting of intravascular ultrasound studies (IVUS). A report of the American College of Cardiology task force on clinical expert consensus documents. J Am Coll Cardiol 2001, 37:1478-92.

28. Briguori C, Anzuini A, Airoldi F, Gimelli G, Nishida T, Adamian M, Corvaja N, Di Mario C, Colombo A: Intravascular ultrasound criteria for the assessment of the functional significance of intermediate coronary artery stenoses and comparison with fractional flow reserve. Am J Cardiol 2001, 87:136-41

29. Abizaid AS, Mintz GS, Abizaid A, Mehran R, Lansky AJ, Pichard AD, Satler LF, Wu H, Kent KM, Leon MB: One-year follow-up after intravascular ultrasound assessment of moderate left main coronary artery disease in patients with ambiguous angiograms. J Am Coll Cardiol 1999, 34:707-15.

30. Cameron A, Kemp HG Jr, Fisher LD, Gosselin A, Judkins MP, Kennedy JW, Lesperance J, Mudd JG, Ryan TJ, Silverman JF, Tristani F, Vlietstra RE, Wexler LF: Left main coronary artery stenosis: angiographic determination. Circulation 1983, 68:484-489.

31. Detre KM, Wright E, Murphy ML, Takaro T: Observer agreement in evaluating coronary angiograms. Circulation 1975, 52:979-986.

32. Vrublevsky AV, Boshchenko AA, Karpov RS: Diagnostics of main coronary artery stenoses and occlusions: multiplane transoesophageal Doppler echocardiographic assessment. Eur J Echocardiogr 2001, 2:170-7.

doi:10.1186/1476-7120-9-19

Cite this article as: Ruzsa et al:: Angiographically borderline left main coronary artery lesions: correlation of transthoracic doppler echocardiography and intravascular ultrasound: a pilot study. Cardiovascular Ultrasound 2011 9:19.

\section{Submit your next manuscript to BioMed Central and take full advantage of:}

- Convenient online submission

- Thorough peer review

- No space constraints or color figure charges

- Immediate publication on acceptance

- Inclusion in PubMed, CAS, Scopus and Google Scholar

- Research which is freely available for redistribution

Submit your manuscript at www.biomedcentral.com/submit
C Biomed Central 